\title{
GPS scintillation over the European Arctic during the November 2004 storms
}

\author{
Robert W. Meggs · Cathryn N. Mitchell • \\ Farideh Honary
}

Received: 20 April 2007 / Accepted: 15 February 2008/Published online: 5 March 2008

(C) Springer-Verlag 2008

\begin{abstract}
Small-scale irregularities in the background electron density of the ionosphere can cause rapid fluctuations in the amplitude and phase of radio signals passing through it. These rapid fluctuations are known as scintillation and can cause a Global Positioning System (GPS) receiver to lose lock on a signal. This could compromise the integrity of a safety of life system based on GPS, operating in auroral regions. In this paper, the relationship between the loss of lock on GPS signals and ionospheric scintillation in auroral regions is explored. The period from 8 to 14 November 2004 is selected for this study, as it includes both geomagnetically quiet and disturbed conditions. Phase and amplitude scintillation are measured by GPS receivers located at three sites in Northern Scandinavia, and correlated with losses of signal lock in receivers at varying distances from the scintillation receivers. Local multi-path effects are screened out by rejection of lowelevation data from the analysis. The results indicate that losses of lock are more closely related to rapid fluctuations in the phase rather than the amplitude of the received signal. This supports the idea, suggested by Humphreys et al. (2005) (performance of GPS carrier tracking loops during ionospheric scintillations. Proceedings Internationsl Ionospheric Effects Symposium 3-5 May 2005), that a wide loop bandwidth may be preferred for receivers operating at auroral latitudes. Evidence from the Imaging Riometer for Ionospheric Studies (IRIS) appears to suggest
\end{abstract}

R. W. Meggs $(\bowtie) \cdot$ C. N. Mitchell

Department of Electronic and Electrical Engineering,

University of Bath, Bath BA1 7AY, UK

e-mail: r.w.meggs@bath.ac.uk

F. Honary

Lancaster University, Lancaster LA1 4WA, UK that, for this particular storm, precipitation of particles in the $\mathrm{D} / \mathrm{E}$ regions may be the mechanism that drives the rapid phase fluctuations in the signal.

Keywords Ionosphere $\cdot$ Scintillation · GPS

\section{Introduction}

Global Navigation Satellite Systems (GNSS) such as the Global Positioning System (GPS), utilise the time taken for L-band signals transmitted by satellites to arrive at a receiver. Using this time measurement and knowledge of the signal velocity and the satellite-to-receiver path lengths, a position solution can be computed. A portion of the signal path passes through the ionosphere, which is the ionised region of the Earth's upper atmosphere. The chief effect of the ionosphere, as far as the GNSS signals are concerned, is to impose an unknown frequency-dependent time delay upon the signal together with an equal and opposite carrier phase advance (Kaplan 1996). Hence an unknown error, proportional to the line integral of ionospheric electron concentration, affects the final position solution. In order to solve for this error, GPS satellites transmit on two carrier frequencies. However, not all GPS receivers are able to receive both carrier frequencies, and thus the error remains unknown for these users.

The electron concentration is highly variable exhibiting both spatial and temporal dependencies of varying scales, and thus the position error due to the ionosphere also varies. A GNSS receiver can only continue to measure the path length to a given satellite, provided it remains 'locked' to that satellite. Thus, not only the accuracy of the position solution can be degraded by the ionospheric delay, but the integrity (i.e. availability) can also be compromised by 
rapid variations in the signal phase and amplitude. This is clearly unacceptable in a safety-of-life application such as an aircraft landing system. The focus of this work is the ionospheric contribution to the rapid fluctuations in phase and amplitude, known as scintillation, in the auroral regions (around $67^{\circ} \mathrm{N}$ ). These are sometimes due to irregularities in the electron density caused by particle precipitation along with the geomagnetic field lines in auroral or arctic regions.

The phenomenon of ionospheric scintillation has been known since late 1940s (Crane 1977), and following the launch of Sputnik 1 in 1957 ionospheric scintillations began to be observed using radio transmissions from artificial satellites. A considerable body of literature accumulated over the next 25 years, much of which is reviewed by Yeh and Liu (1982). In 1978, launches of the first GPS satellites began, and continuously transmitted ranging signals with global coverage became available in the early 1980s. This led to more opportunities to observe the ionosphere. Further, as GPS became fully operational in the mid 1990s, the need arose to examine and, if possible, quantify ionospheric scintillation effects on the GPS navigation solution.

Various mechanisms that cause GPS receivers to lose lock can be identified. For example, the bandwidth of the receiver tracking loop, local multipath conditions and the propagation characteristics of the Earth's atmosphere can all affect a receiver's ability to remain locked to the signals from the GPS satellites. The performance of GPS receiver tracking loops under ionospheric storm conditions has been examined by Skone et al. (2001), for both codeless and semi-codeless receivers. They reported that, for the most severe of the high-latitude storms they examined, the tracking performance of the codeless receiver was significantly degraded, although the effect on the $L 1$ tracking performance for both types of receiver was negligible. Beach and Kintner (2001) describe the development of a GPS ionospheric scintillation monitor based on a commercially available GPS development system. Their receiver is modified to measure signal strength at a sample rate of 50 samples per second. Conker et al. (2003) used models to estimate the instantaneous availability of singlefrequency GPS aircraft navigation, in both scintillation and non-scintillation scenarios, over the continental United States. They reported increased likelihood of loss of lock under scintillation conditions, particularly in the equatorial regions over South America and in the polar region to the north of Canada. Ledvina et al. (2004) have shown that Lband scintillations can form even at mid-latitudes during the main phase of a geomagnetic storm and have suggested that they can also be related to velocity shear and density gradients within the ionosphere. GPS receiver performance with respect to phase scintillation has been investigated by
Morrissey et al. (2004). GPS scintillation over the European high Arctic during the ionospheric storm of October 2003 has been examined by Mitchell et al. (2005), who used a GPS phase and amplitude scintillation receiver located at Ny-Ålesund, Svalbard, Norway. The work presented here is concerned with identifying receiver losses of lock that are likely to be caused by phase and amplitude scintillation as the signal passes through the ionosphere.

\section{Method}

In the summer 2004, three Novatel GSV4004 phase and amplitude scintillation measuring receivers were deployed in Northern Scandinavia and a continuous stream of phase and amplitude scintillation data has since been available for analysis. The scintillation receivers are each fitted with a high-precision oven-controlled oscillator, enabling them to sample the code and carrier phase path lengths on the $L 1$ and $L 2$ carrier frequencies at a rate of $50 \mathrm{~Hz}$ (Van Dierendonck et al. 1996). The sites chosen for the remote receivers are the three mainland European Incoherent Scatter Radar (EISCAT) sites (see Fig. 1), located at Troms $\varnothing\left(69.6^{\circ} \mathrm{N} 19.2^{\circ} \mathrm{E}\right.$ geodetic, $66.107^{\circ} \mathrm{N} 103.366^{\circ} \mathrm{E}$ geomagnetic), Kiruna $\left(67.9^{\circ} \mathrm{N} 20.4^{\circ} \mathrm{E}\right.$ geodetic, $64.279^{\circ} \mathrm{N}$ $102.846^{\circ} \mathrm{E}$ geomagnetic) and Sodankylä $\left(67.4^{\circ} \mathrm{N} 26.6^{\circ} \mathrm{E}\right.$ geodetic, $63.424^{\circ} \mathrm{N} 107.249^{\circ} \mathrm{E}$ geomagnetic). The scintillation receivers were all networked to enable routine data collection at Bath.

Four GPS receivers of the International GPS Service (IGS) network located in the region of the EISCAT sites were also selected for this study, giving a range of baselines of between 12 and $410 \mathrm{~km}$ to the scintillation receivers. The IGS receivers selected were: 'trom', 'tro1', 'kiru' and 'soda', and observation data for these receivers was obtained in 'RINEX' format by FTP download from

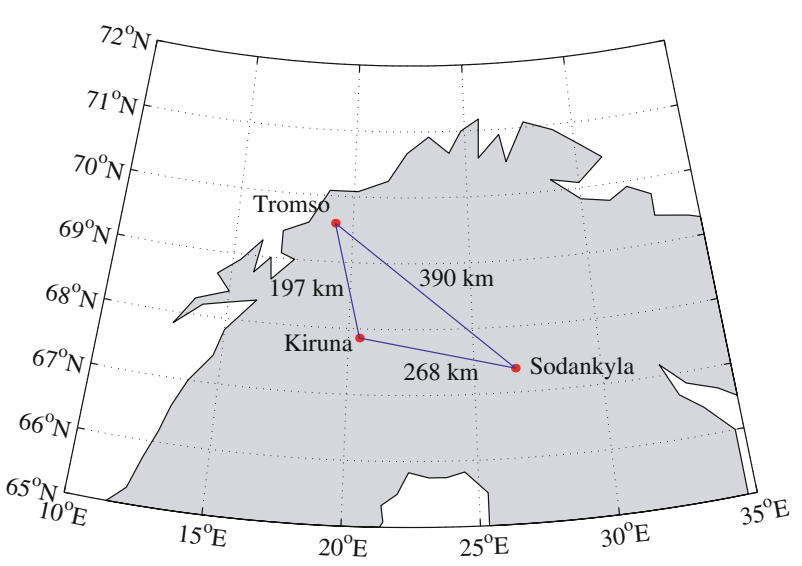

Fig. 1 Map showing locations of scintillation receivers 
the Scripps Orbit and Permanent Array Center (SOPAC) archive at http://www.sopac.ucsd.edu.

Losses of signal lock on all satellite to receiver paths and on both the $L 1$ and $L 2$ frequencies were then identified. The RINEX format does not indicate loss-of-lock explicitly, so phase-lock losses must be inferred from the observation data by post processing. Several approaches to this problem have been described in the literature (Blewitt 1990; Gau and Li 1999). However, in this case, a simple approach was taken. Here, a time series of the geometryfree $(L 4)$ carrier phase combination was formed (Skone et al. 2001), i.e.

$L 4=\left(\frac{\Phi_{1}}{154}-\frac{\Phi_{2}}{120}\right) \frac{c}{10.23}$

where $\phi_{1}$ is the phase path on the $L 1$ frequency, $\phi_{2}$ is the phase path on the $L 2$ frequency, and $c$ is the velocity of light. Then, the local gradient is computed in a 10-point window based on a running median and compared to a threshold value to determine the time indices of the cycleslips.

A difficulty arises in that, at low elevation angles, scintillation effects could be confused with local multipath. An elevation mask of $35^{\circ}$ was therefore used to reduce multipath effects. The choice of a suitable cut-off angle must balance the need to screen out the multipath effects whilst not discarding too much of data that may be ionospherically affected. A further discussion on scintillation and multipath can be found in Van Dierendonck et al. (1996).

In this study, we have focussed on the ionospheric storm period of November 2004, since a disturbed ionosphere is more likely to produce the small-scale irregularities that lead to scintillation (Doherty et al. 2000). The cycle-slips in the IGS receivers were counted over periods of 1, 2, 3, 4, 6 and $8 \mathrm{~h}$. These were then correlated with the maximum phase (sigma-phi) and amplitude (S4) scintillation measured by the scintillation receivers at the EISCAT sites. The scintillation indices, sigma-phi and S4, are defined in terms of the standard deviation of the signal phase or signal power, usually measured over $1 \mathrm{~min}$ (Forte 2005). Two sets of measurements were made: one set for short baselines (in the order of $10-20 \mathrm{~km}$ ) the other set for long baselines (in the order of $200-400 \mathrm{~km}$ ). In this way it is hoped to be able to estimate the temporal and spatial distribution of the scintillation effects.

\section{Results}

In this section, the results for 8 days covering the actual storm, that is from 7 to 14 November 2004 inclusive, are presented. During this period, the Kp index in the daytime was around 2, but reached a maximum of about eight between 8 and 11 November. The Kp index is obtained from a number of mid-latitude magnetometer stations, and quantifies geomagnetic activity on a scale from 0 (low) to 9 (high). In Fig. 2, the upper plot shows the 3-hourly Kp indices (obtained from the World Data Centre, http://www.wdc.rl.ac.uk) over the period of interest. The lower plot shows the number of cycle-slips recorded every hour at the 'soda' IGS receiver, subject to a $35^{\circ}$ elevation mask. A $12 \mathrm{~h}$ moving average of the number of cycle-slips per hour was computed and has been plotted on the cycleslip count. It can be clearly seen that the number of cycleslips increases with the intensity of the storm. Up to 16 cycle-slips were recorded every hour (on all receiver to satellite paths) for each of the IGS receivers. The hourly cycle-slip counts for all the IGS receivers were compared against the $\mathrm{Kp}$ indices, and were found to vary in a similar manner. This gives confidence that the cycle-slips that we have counted here are indeed driven by disturbances on the ionospheric propagation path and not due to local causes. The DST index, which is an index of geomagnetic activity obtained from magnetometer stations near the equator, has also been plotted on the upper plot as a further indicator of activity during the storm period.

The number of cycle-slips on all receiver-to-satellite paths, and both GPS carrier frequencies, were then counted for each of the five IGS receivers. These counts were made over time windows of 1, 2, 3, 4, 6 and $8 \mathrm{~h}$. The phase and amplitude scintillation indices, sigma-phi and $\mathrm{S} 4$, were measured by the three scintillation receivers at the Troms $\varnothing$, Kiruna and Sodankylä sites, and their maximum values were binned over the same time windows as the cycle-slip counts. In this work, we are interested in how the number of cycle-slips correlates with scintillation on various

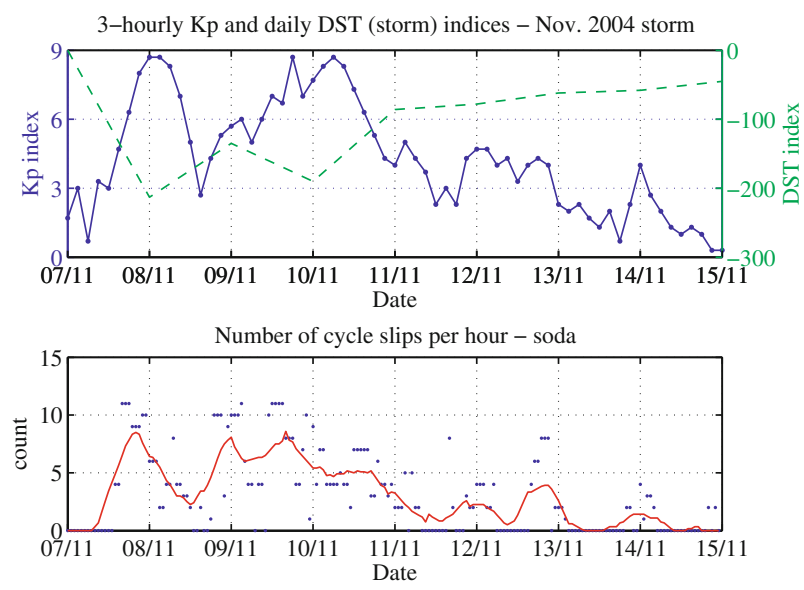

Fig. 2 Geomagnetic conditions and cycle-slip count for the period of 7-15 November 2004. The upper plot shows the 3-hourly Kp and daily DST indices. The lower plot shows the number of cycle-slips per hour, with a $12 \mathrm{~h}$ moving average 
Table 1 Short baselines

\begin{tabular}{ll}
\hline Baseline & $\begin{array}{l}\text { Length } \\
(\mathrm{km})\end{array}$ \\
\hline Tromso-trom/tro1 & 14 \\
Kiruna-kiru & 22 \\
Sodankyla-soda & 12 \\
\hline
\end{tabular}

baselines. First, we will consider short baselines of about 10-20 km. The baselines of interest are shown in Table 1 .

For each time window and each baseline, a time series of the number of cycle-slips in the IGS receiver data was formed and compared with a similar time series of maximum sigma-phi. In every case, a visual examination revealed that there appeared to be a correlation between the number of cycle-slips and sigma-phi on all timescales greater than $1 \mathrm{~h}$. To quantify the relationship between cycle-slips and sigma-phi, the correlation coefficients were computed. Figure 3 (left side) shows the correlation coefficients for each baseline. For all the short baselines, the correlation coefficient can be seen to range from between 0.45 and 0.5 in the $1 \mathrm{~h}$ window, to between 0.7 and 0.8 in the $8 \mathrm{~h}$ window. For the $3 \mathrm{~h}$ time window and above, the correlation index increases more gradually than is the case for the shorter time windows. This suggests that, for short baselines, high values of sigma-phi measured at one location may be a good indication that a receiver at another location will lose lock on the GPS signal. The indication would be improved by taking the number of cycle-slips over the preceding 3 to $8 \mathrm{~h}$. Also, it can be seen that 'trom' and 'tro1' are very closely correlated throughout. This is to be expected as these two IGS receivers are of the same type, and are very close to each other (about $200 \mathrm{~m}$ apart).

The correlation between number of cycle-slips and amplitude scintillation (S4) was also computed, and the correlation coefficients plotted in Fig. 3 (right side). Here, little correlation is observed between the number of cycleslips and the S4 index measured at the nearby scintillation receiver, in all time windows.

We will now consider the cycle-slip/scintillation correlations on baselines in the order of $200-400 \mathrm{~km}$. The six baselines considered are listed in Table 2. Since the correlation between 'trom' and 'trol' was found to be very close in the short baseline case, and they are separated by about $200 \mathrm{~m}$, it is convenient to regard these as one receiver.

Here we again use the number of cycle-slips over periods of 1, 2, 3, 4, 6 and $8 \mathrm{~h}$, then find the maximum sigmaphi and S4 in each of those periods. Time-series plots for the cycle-slip counts and the max sigma-phi were compared in the same way as for the short baselines. Again, a good correlation with the number of cycle-slips was apparent at all timescales in the sigma-phi data, particularly at $3 \mathrm{~h}$ or more where the correlation coefficients range from over 0.5 to about 0.85 . As expected, the correlation with $\mathrm{S} 4$ was less good, ranging from almost zero to just less than 0.4 at all time scales. Quantifying these relationships, we obtain the two plots in Fig. 4. The left-hand plot shows the correlation with sigma-phi, which is quite good at $3 \mathrm{~h}$ and greater. Below $3 \mathrm{~h}$ the correlation drops off to between 0.4 and 0.5 . The best correlation appears to be associated with the shortest baselines, i.e. Kiruna to trom/tro1 $(210 \mathrm{~km})$, so there would appear to be an underlying correlation between the baseline length and the cycle-slip/ sigma-phi correlation. In the right-hand plot, the cycle-slip counts show little correlation with S4 (amplitude scintillation). This is probably due the lack of any large values of amplitude scintillation.

The spatial correlation of the number of cycle-slips with scintillation clearly depends on the size of the disturbing structures. Maps of vertical TEC, corrected for satellite and receiver biases, were constructed for each hour using the MIDAS algorithm Mitchell and Spencer (2003). An example is presented in Fig. 5, which shows the vertical TEC at 02.00 UT on 8 November 2004.

In Fig. 6, the upper plots show data from four beams of the Imaging Riometer for Ionospheric Studies (IRIS), situated at Kilpisjärvi, Finland $\left(69.05^{\circ} \mathrm{N} 20.79^{\circ} \mathrm{E}\right.$ geodetic, $65.853^{\circ} \mathrm{N} 104.301^{\circ} \mathrm{E}$ geomagnetic). IRIS uses a phasedarray antenna with 49 beams to measure absorption at 38.2 MHz. The beams that are directed over Troms $\varnothing$ to the west are beams 9, 16, 23 and 24, all of which show similar
Fig. 3 Short baseline correlation of the number of cycle-slips in the GIS receivers with sigma-phi (left) and S4 (right) measured by the scintillation receivers at the EISCAT sites
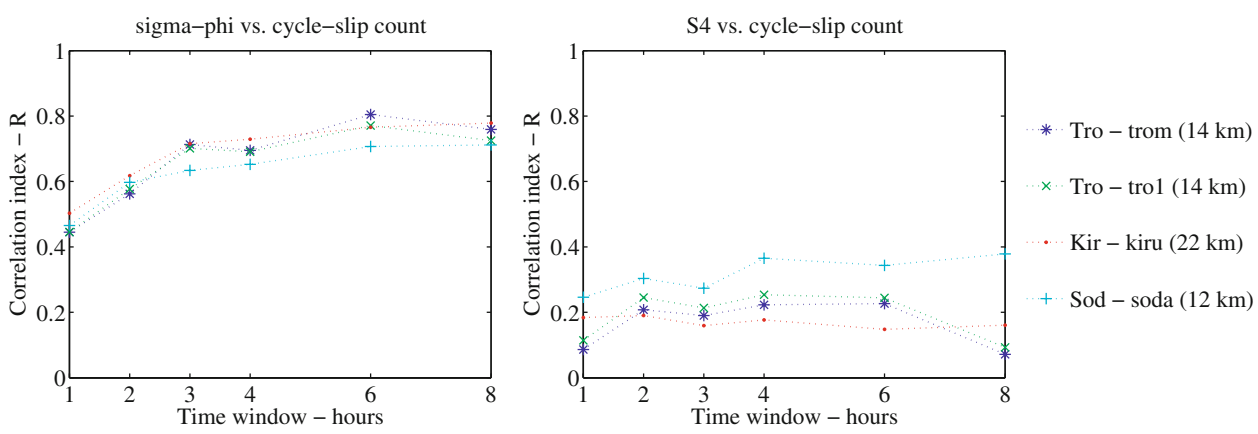
Table 2 Long baselines

\begin{tabular}{ll}
\hline Baseline & $\begin{array}{l}\text { Length } \\
(\mathrm{km})\end{array}$ \\
\hline Troms $\emptyset$-kiru & 205 \\
Troms $\emptyset$-soda & 379 \\
Kiruna-trom/tro1 & 210 \\
Kiruna-soda & 257 \\
Sodankyla-trom/tro1 & 405 \\
Sodankyla-kiru & 247 \\
\hline
\end{tabular}

patterns. In the lower plot the sigma-phi scintillation index has been binned by the hour for the same day ( 8 November). It can be seen that the absorption of the $38.2 \mathrm{MHz}$ signal approximately coincides with peaks of GPS phase scintillation. This suggests that, in the November 2004 storm, the scintillation mechanism is driven by the precipitation of particles that have passed through the F-region and into the D- and E-regions. This is in contrast to the October 2003 storm, described by Mitchell et al. (2005), in which the scintillation was driven by polar convection bringing plasma from the dayside over North America over the pole to the European night side. It is also interesting to note that only beam 24 displays evidence of scintillation between 20.00 and 22.00 UT. This is due to the fact that Cassiopeia, an intense celestial radio source, is within the field of view of this beam and therefore amplitude scintillation can be observed.

\section{Summary and conclusions}

An investigation into the relationship between loss of signal lock on GNSS receivers located in Northern Scandinavia and ionospheric scintillation during the November 2004 storm has been presented in this paper. Phase and amplitude scintillations were measured at three sites in Northern Scandinavia. Four fixed GPS receivers located near to each of the scintillation receivers were selected from the IGS network. The observation data for the IGS receivers were obtained from the SOPAC archive for a period from 7 to 14 November 2004. Losses of phase

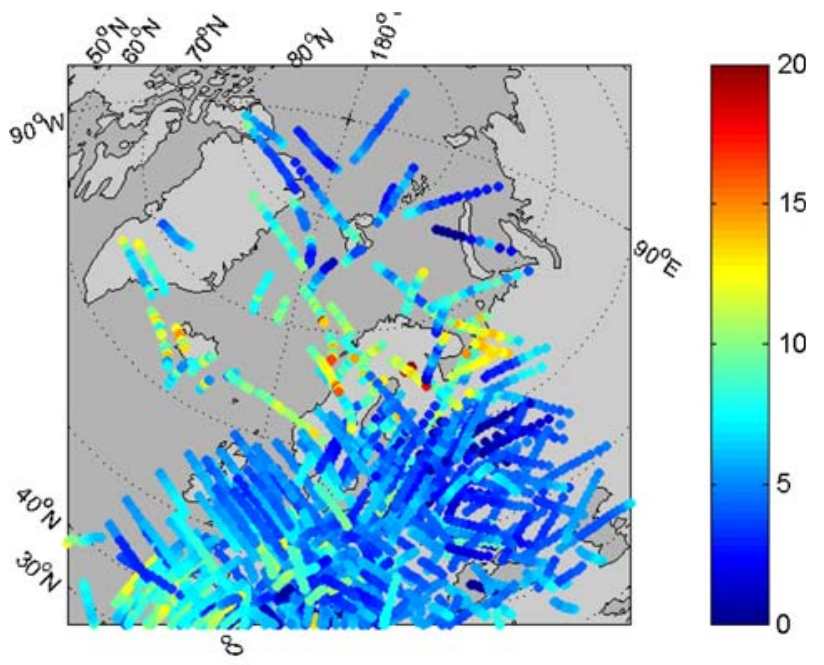

08-Nov-2004 02:00 BIAS CORRECTED VTEC

Fig. 5 Example of a vertical TEC map for 8 November 2004 $02.00 \mathrm{UT}$

lock ('cycle-slips') were then identified in the observation data for these receivers and correlated with phase and amplitude scintillation over a range of timescales and baselines.

It was found that the number of cycle-slips noted in the IGS receivers correlated quite well with sigma-phi measured by the scintillation receivers up to about $20 \mathrm{~km}$ away. This is particularly true for timescales in the range of 3-8 h, in which correlations in the range of $0.6-0.8$ were noted. Similarly, on long baselines $(200-400 \mathrm{~km})$ the correlation was good in the 3 to $8 \mathrm{~h}$ range (about $0.5-0.85$ ), though more variable than in the case of the short baselines. This suggests that sigma-phi may be a good predictor for loss of lock in receivers within a radius of about 20 $100 \mathrm{~km}$ of a scintillation measuring receiver.

The correlation with amplitude scintillation (S4) was found to be low at all timescales and on all baselines. This was probably due to the very low values of S4 typically observed at auroral latitudes; a view supported by Doherty et al. (2000) and Humphreys et al. (2005). However, it should be remembered that S4 is usually calculated over 1 min (Forte 2005). Short but deep fades of less than 1 min duration have nevertheless been observed in the auroral
Fig. 4 Long baseline correlation of the number of cycle-slips in the GIS receivers with sigma-phi (left) and S4 (right) measured by the scintillation receivers at the EISCAT sites
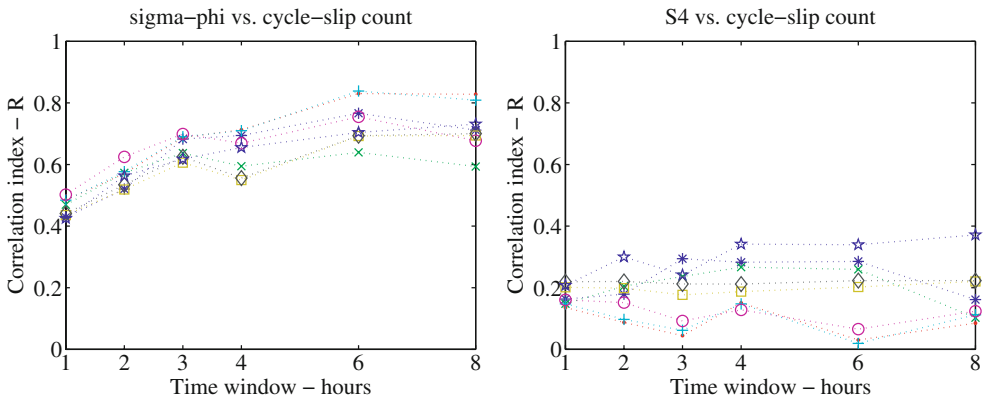

*. Tro - kiru $(205 \mathrm{~km})$

×. Tro - soda $(379 \mathrm{~km})$

Kir - trom $(210 \mathrm{~km})$

$+\cdots$ Kir - tro1 $(210 \mathrm{~km})$

○. Kir - soda $(257 \mathrm{~km})$

曰 Sod - trom $(405 \mathrm{~km})$

仓. Sod - tro1 $(405 \mathrm{~km})$

4. Sod - kiru (247 km) 
Fig. 6 Absorption at $38.2 \mathrm{MHz}$ measured by the 'IRIS' riometer at Kilpisjarvi, Finland (upper), and hourly maximum phase scintillation measured at Tromsø (lower)
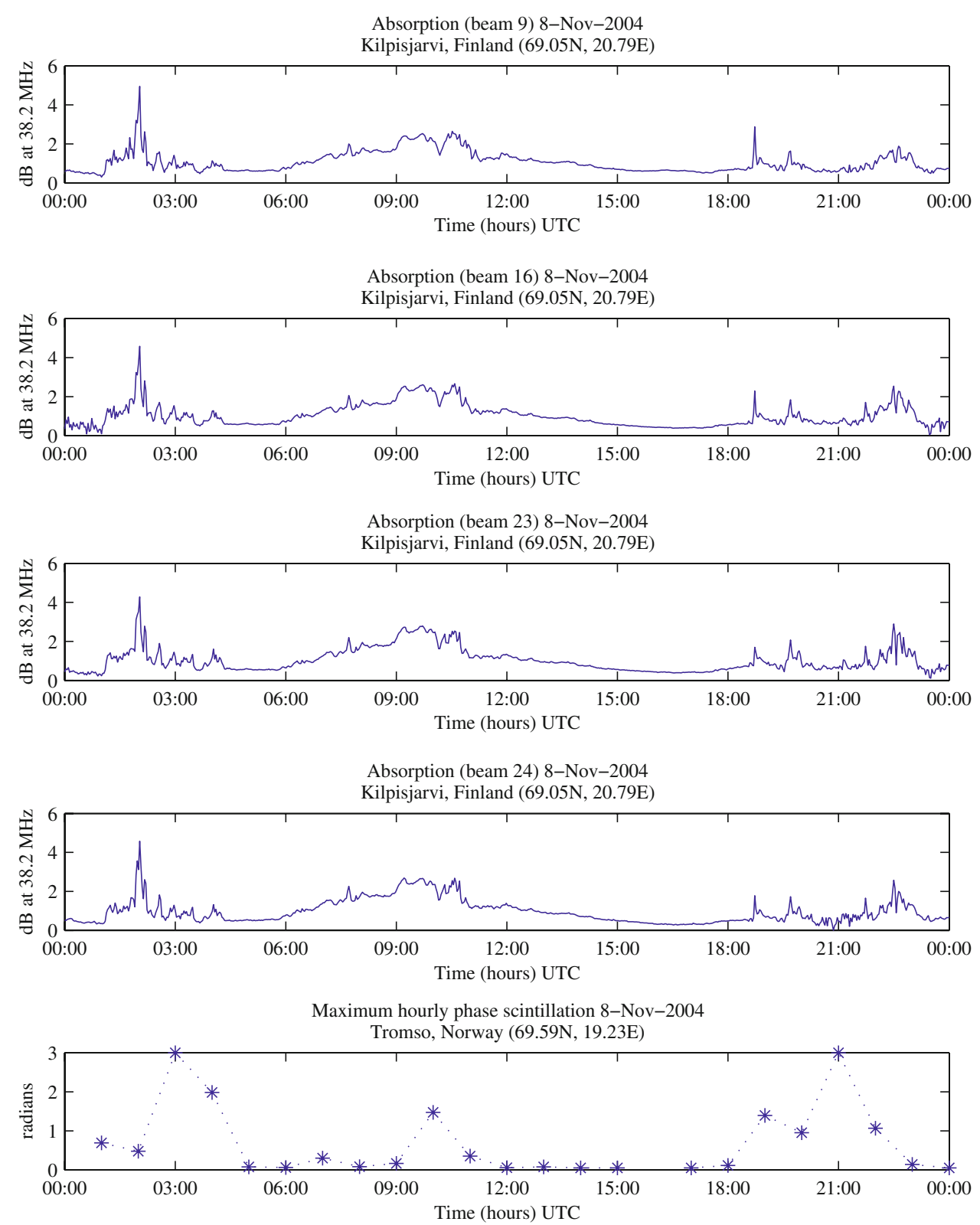

region. Such fades, whilst not significantly increasing the measured S4 index, may nevertheless cause a receiver to lose lock. A case study of a short (sub-minute) but deep fade has been presented by Materassi and Mitchell (2006), who used wavelet techniques in their analysis.

Our data show that phase scintillation was much more prevalent than amplitude scintillation during the November 2004 storm. Humphreys et al. (2005) argue that a narrow passband in the receiver tracking loop (say, of about 3$5 \mathrm{~Hz}$ ) would be unable to maintain signal lock in the presence of these rapid phase variations, and that a higher bandwidth receiver would probably perform better at high latitudes. Our data confirm that this is the case, and it would be interesting to find the optimal bandwidth for high latitudes with a more comprehensive study in the future.
Absorption data at $38.2 \mathrm{MHz}$ were also obtained for 8 November from the IRIS riometer at Kilpisjärvi, Finland. It was found that the variations in absorption approximately coincided with the variations in maximum phase scintillation, leading to the conjecture that the scintillation mechanism in this storm was driven by precipitation of particles at D- and E-region altitudes (80-100 km).

Acknowledgments This work is funded by the UK Engineering and Physical Sciences Research Council (EPSRC). We are grateful to the International GNSS Service (IGS) for the use of GPS data. We also wish to thank the EISCAT Scientific Association for their support. EISCAT is an International Association supported by Finland (SA), France (CNRS), Germany (MPG), Japan (NIPR), Norway (NFR), Sweden (NFR) and the United Kingdom (PPARC). The riometer data originated from the Imaging Riometer for Ionospheric Studies (IRIS), 
operated by the Department of Communications Systems at Lancaster University (UK) in collaboration with the Sodankylä Geophysical Observatory, and funded by the Particle Physics and Astronomy Research Council (PPARC).

\section{References}

Beach TL, Kintner PM (2001) Development and use of a GPS ionospheric scintillation monitor. IEEE Trans Geosci Remote Sens 39(5): 918-928

Blewitt G (1990) An automatic editing algorithm for GPS data. Geophys Res Lett 17(3):199-202

Conker RS, Bakry El-Arini M, Christopher J. Hegarty, Hsiao T (2003) Modelling the effects of ionospheric scintillation on GPS/ satellite-based augmentation system availability. Radio Sci 38(1):1001, doi:10.1029/2000RS002604

Crane, Robert K (1977) Ionospheric scintillation. Proceedings of the IEEE 65(2): 180-199

Doherty PH, Delay SH, Valladares CE, Klobuchar JA (2000) Ionospheric scintillation effects in the equatorial and auroral regions. In: Proceedings ION GPS, 19-22 September 2000, Salt Lake City

Forte B(2005) Optimum detrending of raw GPS data for scintillation measurements at auroral latitudes. J Atmos Solar-Terrestrial Phys 67(12):1100-1109

Gau Y, Li Z (1999) Cycle-slip detection and ambiguity resolution algorithms for dual frequency GPS data processing. Mar Geod 22(4):169-181

Humphreys TE, Psiaki ML, Ledvina BM, Kintner PM (2005) Performance of GPS carrier tracking loops during ionospheric scintillations. Proceedings International Ionospheric Effects Symposium 3-5 May 2005, Alexandria

Kaplan ED (ed) (1996) Understanding GPS: principles and applications, 1st edn. Artech House, Boston, pp 247-251, ISBN 0890067937

Ledvina BM, Kintner PM, Makela JJ (2004) Temporal properties of intense GPS L1 amplitude scintillations at midlatitudes. Radio Science 39, RS1S18, doi:10.1029/2002RS002832

Materassi M, Mitchell CN (2006) Wavelet analysis of GPS amplitude scintillation, a case study. Radio Science (in press)

Mitchell CN, Spencer PSJ (2003) A three-dimensional time-dependent algorithm for ionospheric imaging using GPS. Ann Geophys 46(4):687-696
Mitchell CN, Alfonsi L, De Francesci G, Lester M, Romano V (2005) GPS TEC and scintillation measurements from the polar ionosphere during the October 2003 storm. Geophys Res Lett 32, L12S03, doi:10.1029/2004GL021644

Morrissey TN, Shallberg KW, Van Dierendonck AJ, Nicholson MJ (2004) GPS receiver performance characterization under realistic ionospheric phase scintillation environments. Radio Sci 39 RS1S20, doi:10.1029/2002RS002838, 2004

Skone S, Knudsen K, de Jong M (2001) Limitations in GPS receiver tracking performance under ionospheric scintillation conditions. Phys Chem Earth (A) 26(6-8):613-621

Van Dierendonck AJ, Hua Q, Fenton P, John K (1996) Commercial ionospheric scintillation monitoring receiver development and test results. In: Proceedings annual technical meeting of the Institute of Navigation pp 573-582

Yeh KC, Liu CH (1982) Radio wave scintillations in the ionosphere. Proceedings of the IEEE 70(4): 324-360

\section{Author Biography}

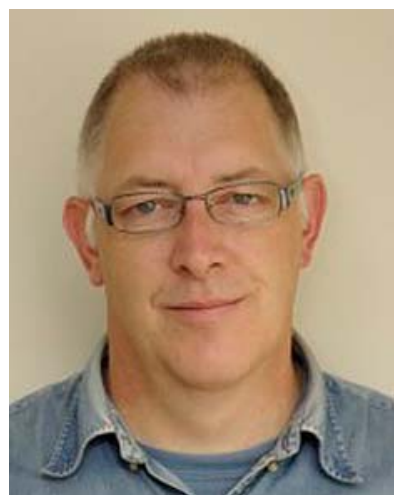

Robert Meggs gained his BSc degree in Mathematics in 1996, by distance learning with the Open University. Whilst studying for his BSc, he worked in a variety of UK-based engineering industries, mainly in the defence sector. He then went on to study Electronics and Communications Engineering at the University of Bath, from where he received his Master's degree in 2001. This was followed in 2005 by the award of his Doctorate by the University of Bath for his work on mapping ionospheric total electron content (TEC) using GNSS signals. He has since worked on loss of receiver lock due to ionospheric scintillation in the auroral regions, and has developed a real-time TEC mapping process for the UK using near real-time GPS data. His current research interests lie in the application of location-based technologies. 